\title{
Biodiesel Production using Oil Extracted from Cooling Pond Wastewater with Esterification of Sulfonated Carbon Catalyst and Transesterification of $\mathrm{Na}_{2} \mathrm{CO}_{3}$ Catalyst
}

\author{
Chandra Fitri Kolakaningrum 1 , Tuty Emilia Agustina ${ }^{2 *}$, Fitri Hadiah² \\ 1 Master Program of Chemical Engineering, Environmental Technology, Universitas Sriwijaya, \\ Jl. Srijaya Negara, Bukit Besar, Palembang 30139, South Sumatera, Indonesia \\ ${ }^{2}$ Chemical Engineering Department, Faculty of Engineering, Universitas Sriwijaya, J. Raya \\ Palembang-Prabumulih Km. 32 Indralaya, Ogan llir 30662, South Sumatera, Indonesia \\ *Corresponding author's e-mail: tuty_agustina@unsri.ac.id
}

\begin{abstract}
While high production of palm oil improves the community economy, it has the potential to damage the environment because it produces the waste containing quite a lot of residual oil. The wastewater generated by this production process flows into the cooling pond before it is further processed in aerobic and anaerobic ponds. The residual oil contained in the cooling pond can be collected and used, e.g. as raw material for biodiesel production. This research aimed to produce biodiesel by utilizing the oil extracted from cooling pond wastewater through the esterification method with a sulfonated carbon catalyst and a transesterification method with the $\mathrm{Na}_{2} \mathrm{CO}_{3}$ catalyst. The sulfonated carbon catalyst was made from the palm kernel shells as a solid waste of the palm oil plant. In order to study the optimum amount of catalyst usage, the catalyst ratio was varied, i.e. $8-16 \%$ for the esterification process and $1-3 \%$ for the transesterification process. The reuse performance of sulfonated carbon catalysts was varied three times. On the basis of the research results, sulfonated carbon catalysts were proven to be effective as heterogeneous catalysts in the esterification process because they can reduce acid level to below $5 \mathrm{mg} \mathrm{KOH} / \mathrm{g}$ oil. The sulfonated carbon catalyst ratio of $12 \%$ was the optimum ratio which can reduce the acid level to $4.62 \mathrm{mg}$ $\mathrm{KOH} / \mathrm{g}$ oil. The reuse of sulfonated carbon can reduce the acid level to $6.9 \mathrm{mg} \mathrm{KOH} / \mathrm{g}$ oil at the first reuse. In the transesterification process, the optimum ratio of the $\mathrm{Na}_{2} \mathrm{CO}_{3}$ catalyst of $3 \%$ was found. The biodiesel produced has met the biodiesel characteristics of National Indonesian Standard (SNI of 7182:2015) with the saponification number of $197.18 \mathrm{mg} \mathrm{KOH} / \mathrm{g}$ oil, free glycerol of $0.09 \%$, FAME content of $96.79 \%$, and density of $886 \mathrm{~kg} / \mathrm{m}^{3}$.
\end{abstract}

Keywords: cooling pond wateswater, esterification, transesterification, sulfonated carbon, $\mathrm{Na}_{2} \mathrm{CO}_{3}$, biodiesel

\section{INTRODUCTION}

Ministerial Regulation Number 12 of 2015 concerning the Biofuel Provision, Utilization, and Trading as Other Fuels states that began in early 2020 , will be applied to B30 diesel oil, increasing the demand for biodiesel. The industries in Indonesia supplying biodiesel use crude palm oil (CPO) and palm kernel oil (PKO) as raw materials. Besides $\mathrm{CPO}$ and $\mathrm{PKO}$, palm oil liquid waste can be utilized as a raw material in the production of biodiesel. On the basis of the report from The Indonesia Oil Palm Plantations
Fund Management Agency (BPDPKS) in 2019, $1000 \mathrm{~kg}$ of fresh fruit bunches produced $583 \mathrm{~kg}$ of palm oil mill effluent (POME) liquid waste. In the processing of palm oil, CPO POME wastewater is in the form of condensate, while its solid waste is empty bunches, shells, and fibers. The palm oil industry in South Sumatra processes palm oil waste before disposing it to the environment. Liquid wastewater is treated utilizing aerobic ponds to degrade its wastewater components, while solid waste is spread in oil palm plantations as fertilizer. This wastewater treatment, however, is not optimal and does not meet the environmental 
quality standards. The liquid wastewater treatment using aerobic ponds needs a large area, takes a long time, and causes evaporation of methane directly into the atmosphere (Agustina et al., 2019). Furthermore, solid waste treatment as fertilizer does not significantly increase nutrients and palm oil production (Susilawati et al., 2015).

Nuryanti et al (2019) described that the amount of oil and fat content in the cooling pond (the pond used before the aerobic pond) is $9,600 \mathrm{mg} / \mathrm{l}$. This amount exceeds the acceptable threshold for oils and fats of $25 \mathrm{mg} / \mathrm{l}$. It shows that oil is still found in the cooling pond which will evaporate methane into the environment when processed in the aerobic pond. Since methane has the potential to harm the atmosphere, the oil must be processed before entering the aerobic pond. The oil contained in the cooling pond wastewater is a vegetable oil that can be utilized as biodiesel (Kusumawardani et al., 2019). However, since the free fatty acid (FFA) content in the cooling pond wastewater remains high, it must be treated through two processes, including esterification and transesterification that can be assisted by catalysts. Catalysts are used in biodiesel processing to make the process run faster under low operating conditions.

A study by Ngaosuwan (2016) used the catalyst of coffee residue in the biodiesel production process. The coffee residue has a carbon-based catalyst which is heterogeneous. The resulting conversion of ester oil is $71.5 \%$, indicating that a carbon-based catalyst is suitable as an esterification catalyst. Besides, heterogeneous catalysts are chosen in biodiesel production because the separation between biodiesel, catalyst, methanol, and glycerol is easier compared to the use of homogeneous catalysts (Sani et al., 2014), and the catalyst can be reused in the next biodiesel production process. One of the carbon-based catalysts is palm oil solid waste. Husin's study (2011) utilized palm oil waste comprising palm fiber and empty bunches as the catalyst (Husin et al., 2011). Another palm oil solid waste of palm kernel shells was used in this study to find out its ability as a biodiesel catalyst.

$\mathrm{Na}_{2} \mathrm{CO}_{3}$ can be taken from by product of $\mathrm{CO}_{2}$ absorption process by $\mathrm{NaOH}$. $\mathrm{Na}_{2} \mathrm{CO}_{3}$ is difficult to regenerate into initial hydroxides due to high thermal stability. Many studies on this alkaline salt have been carried out, one of which is as a transesterification catalyst. $\mathrm{Na}_{2} \mathrm{CO}_{3}$ was found in the study conducted by Malins (2018) which produced biodiesel yield above $95 \%$ made of rapeseed oil at an operating temperature of $65^{\circ} \mathrm{C}$, the reaction time of 360 minutes, and a molar ratio of oil to methanol of $1 / 8$.

In this study, the oil in the cooling pond was withdrawn and utilized as raw material for biodiesel production using the esterification and transesterification methods. The esterification catalyst of sulfonated carbon from palm kernel shells can reduce the palm oil solid waste. The difference of transesterification catalyst in the form of $\mathrm{K}_{2} \mathrm{CO}_{3}$ in producing biodiesel was examined. The effect of the catalyst ratio of esterification, transesterification, and the reuse performance of the sulfonated carbon catalysts were studied.

\section{MATERIALS AND METHODS}

\section{Materials and preparation}

Sulfonated carbon, n-hexane, and acetone technical from Bratachem, PP indicator, $\mathrm{KOH}-$ ethanol titrant solution, methanol $99 \%$, ethanol, chloroform, $\mathrm{K}_{2} \mathrm{CO}_{3}$ were supplied from Sigma Aldrich and cooling pond wastewater from the palm oil industry (South Sumatra) were used.

Sulfonated carbon and $\mathrm{K}_{2} \mathrm{CO}_{3}$ were heated at a temperature of $105^{\circ} \mathrm{C}$ for 1 hour to remove their water content. Then, the used sulfonated carbon was washed using acetone and dried at a temperature of $105^{\circ} \mathrm{C}$ for 1 hour to remove the acetone which had dissolved oil, methanol, and water in the catalyst pores.

\section{Materials characterization}

Before the esterification process, sulfonated carbon was characterized by X-Ray diffraction (XRD) and Scanning Electron Microscope (SEM). XRD analysis was carried out to see the crystal structure based on the information on the peaks of the scattering angle (Rigaku MiniFlex600) and SEM analysis to see the surface morphology of material (SEM Hitachi SU3500).

\section{Extraction procedure}

During the extraction procedure, $500 \mathrm{ml}$ of cooling pond wastewater oil was mixed with $\mathrm{n}$-hexane with volume ratio of cooling pond wastewater: n-hexane of 1:1. Then, the mixture of cooling pond wastewater and n-hexane was 
stirred for 1 hour. After stirring, the extraction mixture was allowed to stand for 3 days in a separating funnel. After forming layers of mixture of oil-solvent and impurities, the mixture of oil-solvent was separated from impurities.

\section{Distillation procedure}

The waste oil and solvent were separated by distillation at $\mathrm{T}=75^{\circ} \mathrm{C}$. The waste of the cooling pond had been separated from the solvent and ready for use.

\section{Esterification procedure}

During the esterification procedure, $125 \mathrm{ml}$ of waste oil was heated to $\mathrm{T}=65^{\circ} \mathrm{C}$ and the FFA was measured. Meanwhile, methanol with a molar ratio of methanol: oil of 12:1 and a sulfonated catalyst of palm kernel shells of $8 \%$ (wt/wt oil) was heated to $\mathrm{T}=65^{\circ} \mathrm{C}$. The waste oil, methanol, and catalyst were mixed and stirred for 3 hours. Besides being stirred, the reaction temperature was also maintained at $\mathrm{T}=65^{\circ} \mathrm{C}$. Within 3 hours, the mixture was sampled every 30 minutes and then put into a centrifuge. After 3 hours of heating, the ester oil and catalyst were allowed to stand for a while to decrease the temperature. Then, both of them were put into the centrifuge. The ester oil that had been separated from the catalyst was heated to $\mathrm{T}=65^{\circ} \mathrm{C}$. The FFA of triglyceride oil was measured. Each sample and the mixture of esterification-catalyst oil was put into a centrifuge at $3500 \mathrm{rpm}$ for 5 minutes. The procedure for the esterification process above was also performed for variations of a sulfonated catalyst of palm kernel shells of $10-16 \%$ (wt/wt oil). Then, the optimum variations of the sulfonated catalyst of palm kernel shells were determined to be used in the transesterification process.

\section{Transesterification procedure}

In the course of the transesterification procedure, $250 \mathrm{ml}$ of ester oil was heated to $\mathrm{T}=$ $65^{\circ} \mathrm{C}$ and then the FFA was measured. Meanwhile, a volume of methanol $=20 \%$ of the oil and $1 \% \mathrm{Na}_{2} \mathrm{CO}_{3}$ catalyst (wt/wt oil) were heated to $\mathrm{T}=65^{\circ} \mathrm{C}$. The ester oil, methanol, and catalyst were mixed and stirred for 1 hour. Besides being stirred, the reaction temperature of the mixture was also maintained at $\mathrm{T}=65^{\circ} \mathrm{C}$. Each sample was ensured to be stirred at the same speed. Subsequently, the mixture of biodiesel and catalyst was put into a centrifuge. The biodiesel mixture that had been separated from the catalyst was put into a separating funnel and allowed to stand for 1 day until 2 layers were formed. The top layer (pure biodiesel) was washed using distilled water, then separated from the bottom layer. Pure biodiesel was heated at $\mathrm{T}=105^{\circ} \mathrm{C}$ to remove its water content. Each sample and the biodieselcatalyst mixture were put into the centrifuge at $3500 \mathrm{rpm}$ for 5 minutes. The process procedure of transesterification above was also carried out for variations of the $\mathrm{Na}_{2} \mathrm{CO}_{3}$ catalyst of $1.5-3 \%$ (wt/ wt oil). The characteristics of biodiesel, including the FFA content, FAME (Fatty Acid Methyl Ester) content, density, kinematic viscosity, free glycerol, total glycerol, saponification number, and oxidation stability were analyzed. Table 1 shows biodiesel characteristics by the National Standarization Agency (BSN) Indonesia in SNI Biodiesel of 7182:2015.

\section{Analysis of FFA content by titration}

The FFA was measured by titration using $\mathrm{KOH}$-ethanol solution as the titrant; 0.5 grams of oil that would be measured for its FFA was weighed into the Erlenmeyer flask. Then $25 \mathrm{ml}$ of ethanol, $25 \mathrm{ml}$ of chloroform, and 10 drops of PP indicator were put into an Erlenmeyer flask. The solution was stirred with a magnetic stirrer then titrated with a $\mathrm{KOH}$-ethanol solution until it turned pink (Kusumawardani, 2019). The changes in FFA over time resulting in conversions rate was calculated by the formula (Balan, 2020):

$$
\text { FFA Conversion }(\%)=\frac{\text { Initial FFA- Final FFA }}{\text { Initial FFA }} \times 100 \%
$$

Table 1. Biodiesel characteristics of National Indonesian Standard (SNI of 7182:2015)

\begin{tabular}{|c|c|c|c|}
\hline No. & Test parameters & $\begin{array}{c}\text { Unit, min/ } \\
\mathrm{max}\end{array}$ & Requirements \\
\hline 1. & FFA content & $\mathrm{mg} \mathrm{KOH} / \mathrm{g}$ oil & Maximum 0.5 \\
\hline 2. & FAME content & $\% \mathrm{wt}$ & Minimum 96.5 \\
\hline 3. & Density & $\mathrm{kg} / \mathrm{m}^{3}$ & $860-890$ \\
\hline 4. & Kinematic Viscosity & $\left(\mathrm{mm}^{2} / \mathrm{s}\right) \mathrm{cSt}$ & $2.3-6$ \\
\hline 5. & Free Glycerol & $\% \mathrm{wt}$ & Maximum 0.02 \\
\hline 6. & Total Glycerol & $\% \mathrm{wt}$ & Maximum 0.24 \\
\hline 7. & $\begin{array}{c}\text { Saponification } \\
\text { Number }\end{array}$ & $\mathrm{mg} \mathrm{KOH} / \mathrm{g}$ oil & $196-206$ \\
\hline 8. & Oxidation Stability & hours & Minimum 6 \\
\hline
\end{tabular}




\section{RESULTS AND DISCUSSION}

\section{Characterization of sulfonated carbon of palm kernel shells}

Sulfonated carbon was chosen as a catalyst in the esterification process because it has good mechanical properties, thermal stability, and high selectivity (Sangar et al., 2019). The characterization of the structure and size of the solid crystals was carried out using XRD. The peak values obtained from the XRD data could be compared using the X-ray diffraction peaks for each material. The XRD method is able to identify the element content in the sample by comparing the diffraction data and the database. Each crystal field of the element consists of particular distinctive peaks (Mursal et al., 2017).

Figure 1 shows the XRD results that sulfonated carbon catalysts have a diffraction pattern with a peak at $2 \theta: 24,59^{\circ}$. This peak indicates the presence of sulfonated carbon. This peak is the same that in Nata's (2017) study which used sulfonated carbon as a transesterification was at $2 \theta$ $: 20^{\circ}-30^{\circ}$, Niu's (2018) study at $2 \theta: 15^{\circ}-30^{\circ}$, and Lathiya's (2018) study at $2 \theta: 27,24^{\circ}$ which used sulfonated carbon as a transesterification catalyst.

Figure 2 shows the detailed surface morphology of carbon catalyst with SEM magnification of 15 thousand times. Figures $2 \mathrm{a}$ and $2 \mathrm{~b}$ present carbon before sulfonation. Figure $2 \mathrm{a}$ shows a large aggregate with a flat smooth surface, unequally large holes, and the surface morphology is not the same shape. An interesting change in surface morphology was observed when carbon was treated with $\mathrm{H}_{2} \mathrm{SO}_{4}$. This change is shown in Figures $2 \mathrm{c}$ and $2 \mathrm{~d}$. The morphology of carbon sulfonated shows a rough surface, equal holes, and each particle is evenly distributed and homogenous. This

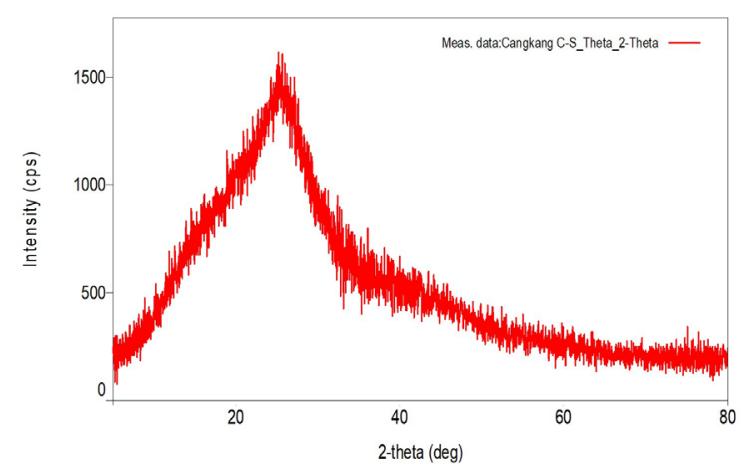

Figure 1. XRD of sulfonated carbon means that the sulfonation process makes the catalyst more uniform and increases the pores of catalyst. It caused the diffusion of reactant into catalyst will increase.

\section{The effect of sulfonated carbon catalyst ratio and reaction time on the FFA of oil in the esterification process}

Figure 3 shows that the longer the reaction time, the higher the conversion of the FFA of the oil. The highest conversion of FFA of the oil occurred at the reaction time of 180 minutes at $77.69 \%$. The longer the reaction time, the more FFA will be converted into esters.

This reaction time, however, will meet its optimum peak, in which if the reaction time is extended, the conversion of the FFA will be stable and not increase or decrease due to the back-andforth reactions (Ni et al., 2019). Figure 3 also shows that the optimum catalyst ratio was $12 \%$. The increased catalyst ratio did not increase the conversion of the FFA. The increased catalyst ratio was followed by the increased active site of the catalyst, causing methanol and oil to spread and not meet at the same active site (Sangar et al., 2019). A study by Abdelrahman (2016) used milk thistle plant oil (low FFA content) with the methanol: oil mole ratio of 15 , and the optimum sulfonated carbon catalyst ratio of $6 \%$ from a range ratio of $1-7 \%$. Meanwhile, Niu's (2018) study used pure oleic acid (low FFA content), with the methanol: oil mole ratio of 12 , and the optimum sulfonated carbon catalyst ratio of $12 \%$ of a range ratio of $0-14 \%$.

At a catalyst ratio of $12 \%$, the FFA declined to $4.62 \mathrm{mg} \mathrm{KOH} / \mathrm{g}$ oil. This FFA met the requirements for the recommended FFA of oil to be processed for transesterification, which is below $5 \mathrm{mg} \mathrm{KOH} / \mathrm{g}$ oil (Wahyuni, 2015). Besides the catalyst ratio of $12 \%$, the ratio of $10 \%$ also fulfills the entry requirements for the transesterification process as shown in Figure 4.

\section{The effect of sulfonated carbon catalyst and reused catalyst performance on the FFA of oil in the esterification process}

The advantage of heterogeneous catalysts is their ability to be reused in the esterification process to reduce production costs. Initially, the sulfonated carbon catalyst was washed using acetone 
a)

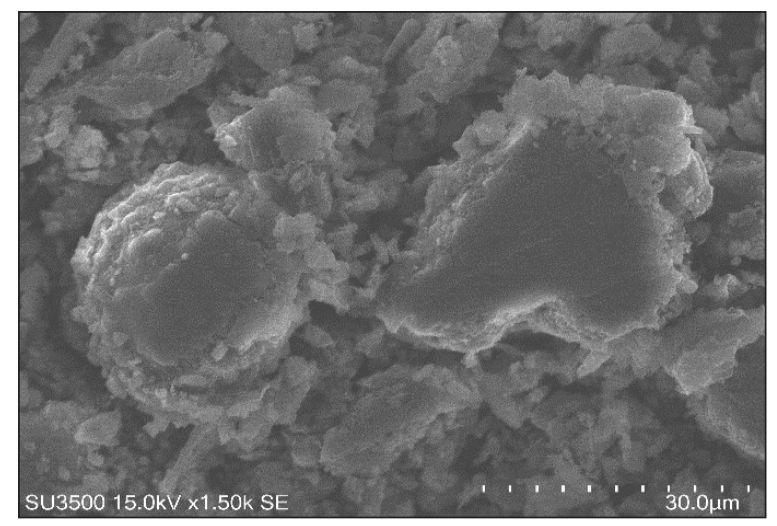

c)

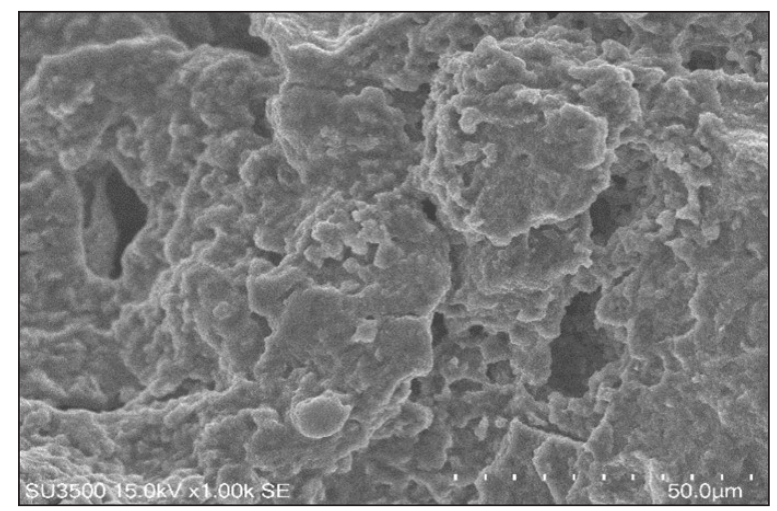

b)

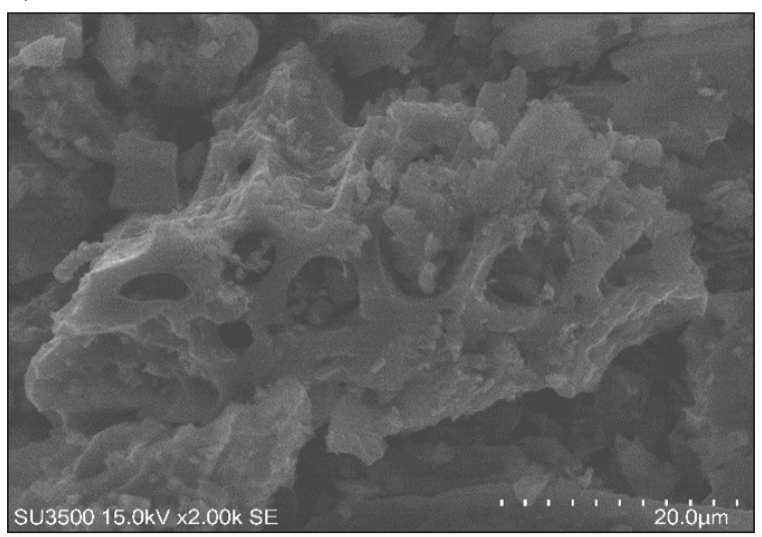

d)

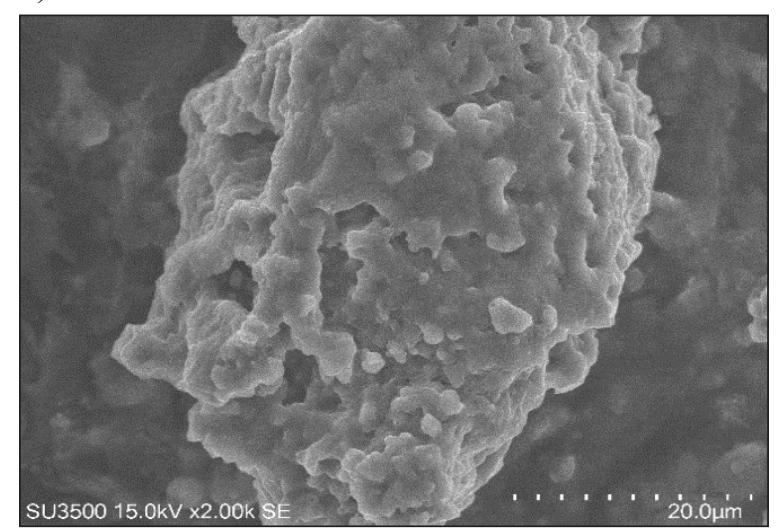

Figure 2. SEM results of carbon from palm kernel shells (a and b); sulfonated carbon (c and d)

to remove oil and methanol which still adhered to the surface of the catalyst. Subsequently, the catalyst was put in an oven to remove the acetone, methanol, and water. The sulfonated carbon catalyst was reused three times.

Figure 5 shows that the reused catalysts produced a lower conversion of FFA compared to the fresh catalysts. FFA conversion was decreased from $77.69 \%$ to $40.08 \%$ after the catalyst was reused three times. This decrease indicates a reduction in the $-\mathrm{SO}_{3} \mathrm{H}$ active group attached to the

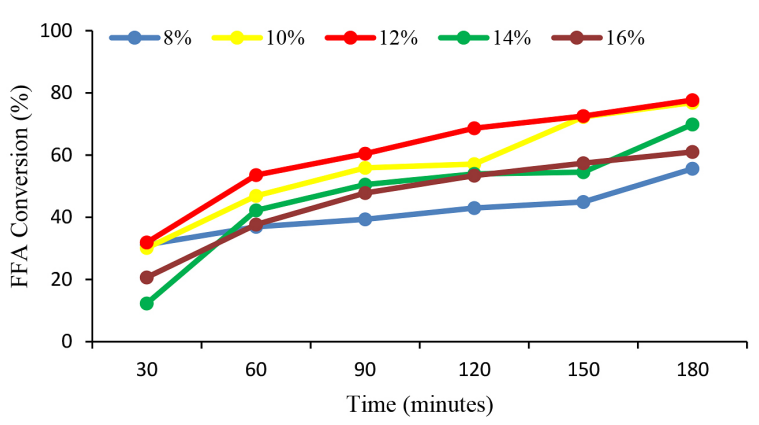

Figure 3. The Effect of esterification time of FFA coversion in fresh sulfonated carbon catalyst catalyst, reducing the acidic atmosphere in the esterification reaction (Nata et al., 2017)Sangar's (2019) study also showed a decrease in the conversion of the FFA from $96.5 \%$ to $75 \%$ after the catalyst was reused seven times. Besides, the decreased sulfur content from $4.2 \%$ to $1.8 \%$ became the main factor for the decline in oil conversion. Sangar's (2019) study used the methanol: oil mole ratio of 18 to assist in the FFA conversion. Besides, Niu's (2018) study showed a decrease in esterification efficiency from $96 \%$ to $28 \%$ after the catalyst was reused five times.

The reused catalyst has insufficient capacity to reduce the FFA of oil. Figure 6 shows that the FFA of the oil using the reused catalysts did not meet the requirements to enter the transesterification process.

\section{Esterification reaction kinetics}

The reaction rate was affected by the concentration of the reactants, the surface area of the reactants, the reaction temperature, and the size of the catalyst used (Otera, 2009). 


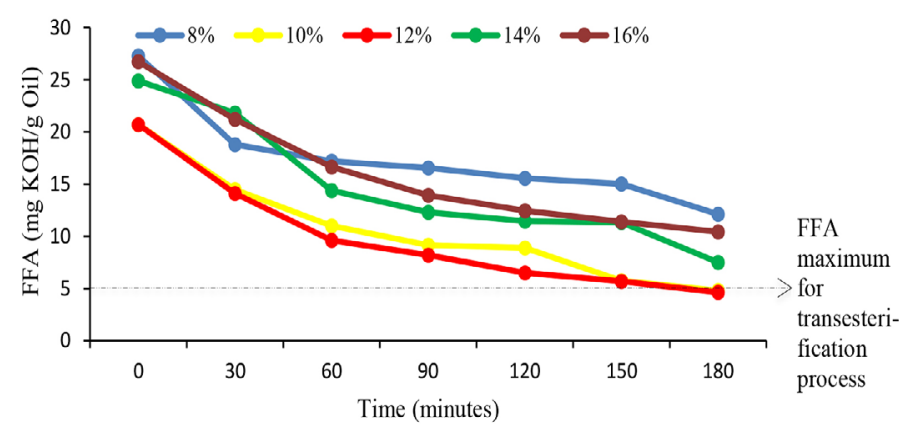

Figure 4. The effect of esterification time on the FFA of the ester oil

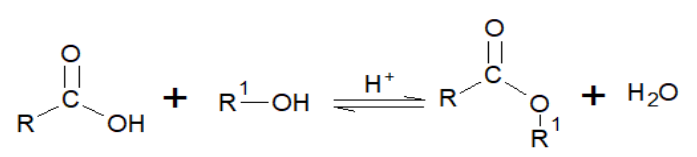

FFA Alcohol

Ester

Water

The esterification reaction as shown used the same surface area of the reactants, the reaction temperature, and the size of the catalyst, while the value of FFA concentration in oil changed over time. The mole ratio of methanol: oil $=12: 1$ with excess methanol with a fixed methanol concentration. Therefore, the esterification reaction used the first order pseudo to determine the reaction kinetics. First-order reaction kinetics were also found in Ni's (2019) study, where the alcohol used was constant, allowing a linear equation.

In order to determine the reaction rate, three steps are required. The first, FFA concentration $\left(\mathrm{C}_{\mathrm{A}}\right)$ are calculated at $\mathrm{t}=0-180$ minutes, where:

$$
r_{A}=-k \cdot C_{A}
$$

$$
\frac{d C_{A}}{d t}=-k \cdot C_{A}
$$

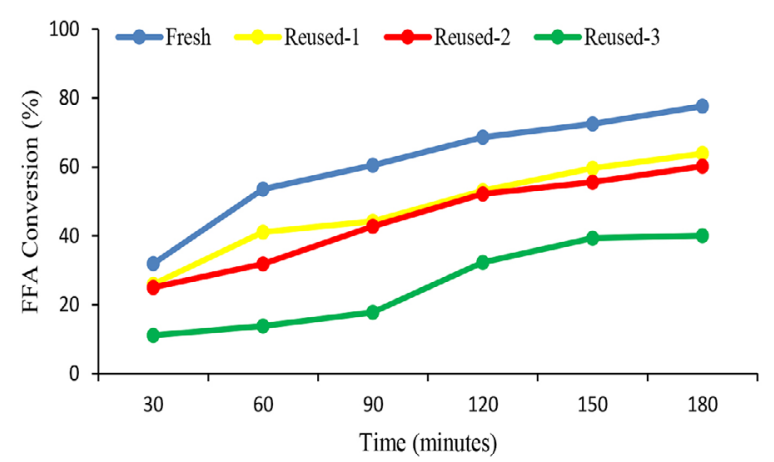

Figure 5. The Effect of esterification time on the FFA conversion of the ester oil at a catalyst ratio of $12 \%$

$$
\int_{C_{A 0}}^{C_{A}} \frac{d_{C A}}{C A}=-k \int_{0}^{t} d t
$$

$$
\begin{gathered}
\left.\ln C_{A}\right|_{C_{A 0}} ^{C_{A}}=-k t \\
\ln C_{A}-\ln C_{A 0}=-k t \\
\ln \left(C_{A 0}-C_{A}\right)=k . t
\end{gathered}
$$

where: $C_{A 0}=$ the initial FFA concentration (mol/l); $t=$ esterification time (minute); $C_{A}=$ the final FFA concentration $(\mathrm{mol} / \mathrm{l})$; $k=$ reaction rate constant $\left(\right.$ minute $\left.^{-1}\right)$. The second step, the $\mathrm{C}_{\mathrm{A}}$ value and $\mathrm{t}$ are plotted onto a graph to obtain the $\mathrm{k}$ value. Figure 7 shows the $\mathrm{R}^{2}$ value of 0.9372 and the equation

$$
y=a x+b
$$

where: $a=$ slope

$b=$ intercept;

$y=0,0091 x$, with the slope $=k$;

then $k=0,0091$. In the last step, reaction rate can be calculated as

$$
\begin{gathered}
r_{A}=-k \cdot C_{A} \\
r_{A}=-(0.0091 \times 0.0704) \\
r_{A}=-6.4 \times 10^{-4}
\end{gathered}
$$

$\mathrm{Na}_{2} \mathrm{CO}_{3}$ is alkaline salts that are good as transesterification catalysts because they have a strong ability to reduce FFA (Malins, 2018). Figure 8 shows that the highest conversion FFA of 


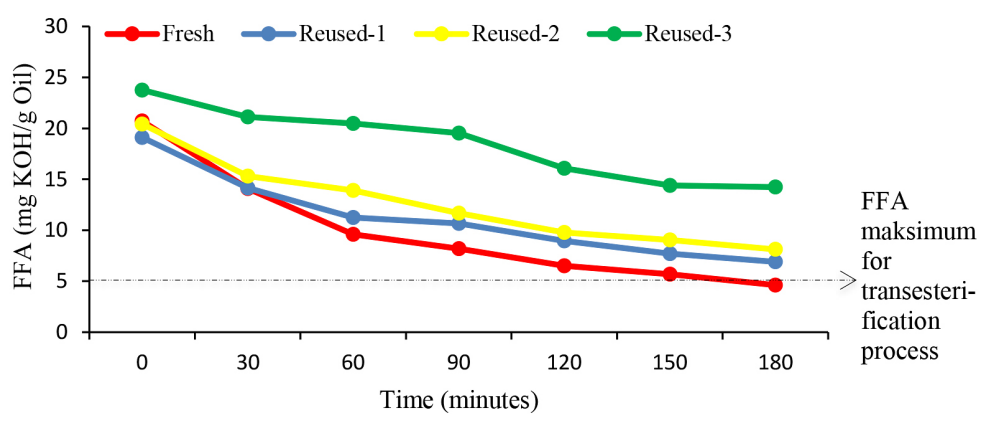

Figure 6. The effect comparison of esterification time on the FFA of the ester oil between the fresh and reused catalyst

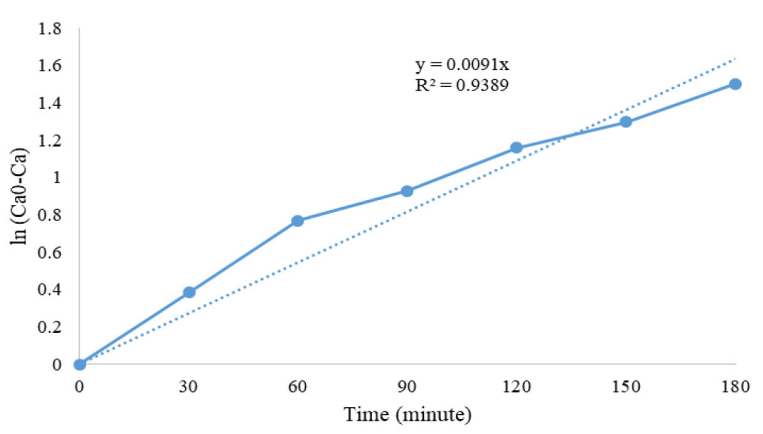

Figure 7. Esterification reaction kinetics the effect of $\mathrm{Na}_{2} \mathrm{CO}_{3}$ catalyst ratio on the FFA of biodiesel in the transesterification process

biodiesel was $85.01 \%$ at a $\mathrm{Na}_{2} \mathrm{CO}_{3}$ catalyst ratio of $3 \%$. Figure 9 shows that the FFA content at $\mathrm{Na}_{2} \mathrm{CO}_{3} 3 \%$ was $0.712 \mathrm{mg} \mathrm{KOH} / \mathrm{g}$ Oil. This FFA content is still high because $\mathrm{Na}_{2} \mathrm{CO}_{3}$ can dissolve in that only about $10 \%$. The low solubility of $\mathrm{Na}-$ ${ }_{2} \mathrm{CO}_{3}$ in methanol leads to a difficult reaction between reactants (Malins, 2018). The conversion of the FFA of the biodiesels decreased in the addition of $\mathrm{Na}_{2} \mathrm{CO}_{3}$ catalyst ratio due to the high ratio of the catalyst to saturate methanol. Therefore, FFA and methanol are difficult to react with each other (Chanakaewsomboon et al., 2019). The reactivity of $\mathrm{Na}_{2} \mathrm{CO}_{3}$ requires a transesterification time of more than 1 hour so that the maximum FFA content can be achieved.

The biodiesel using $\mathrm{Na}_{2} \mathrm{CO}_{3}$ catalyst had not met the SNI for biodiesel. A high FFA can lead to an increase in the corrosion rate in machines (Laila et al., 2017). It is different from the study conducted by Mantovani (2020) which used $\mathrm{CaO}$ as a transesterification catalyst. The FFA of oils to be processed using a $\mathrm{CaO}$ catalyst must be below $2 \%$. Probably, because the difference of raw material, this study needs a longer reaction time and a higher amount of a transesterification catalyst.

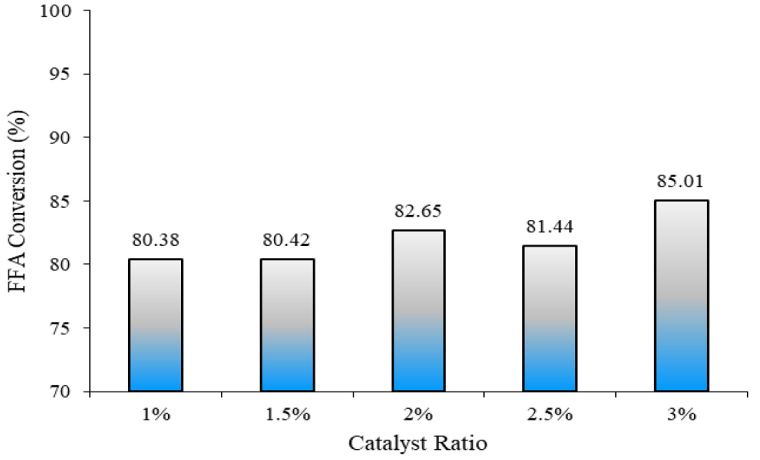

Figure 8. The effect of catalysts ratio on the FFA conversion of biodiesel

\section{The effect of $\mathrm{Na}_{2} \mathrm{CO}_{3}$ catalyst ratio on the FAME content in the transesterifi- cation process}

The FAME content is highly related to FFA. If the oil has a high FFA, then the FAME content will be low and vice versa. The FAME content in Figure 10 shows that the $\mathrm{Na}_{2} \mathrm{CO}_{3}$ catalyst has a high percentage. Besides being affected by the FFA, the FFA content is also affected by the catalyst.

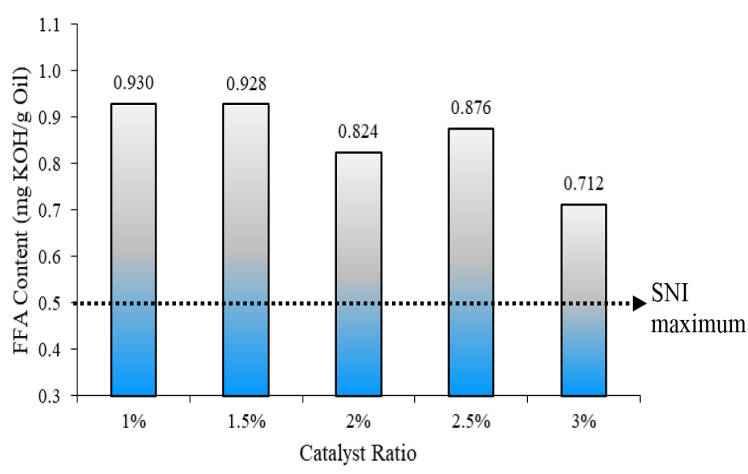

Figure 9. The effect of catalysts ratio on the FFA content of biodiesel 
The more reactive the catalyst is, the easier it is to react. $\mathrm{Na}_{2} \mathrm{CO}_{3}$ which has the $\mathrm{Na}$ element, is characterized by high reactivity. It is because, in the alkaline group, the greater the atomic number, the more reactive the compound is (Nuryono et al., 2018).

$\mathrm{Na}_{2} \mathrm{CO}_{3}$ catalyst is not hygroscopic so that the FFA content fluctuation is caused by the short transesterification time. The highest FAME content was $96.80 \%$ on a $2.5 \% \mathrm{Na}_{2} \mathrm{CO}_{3}$ catalyst. This value has met the SNI for Biodiesel, which is a minimum of 96.5. In Malins' (2018) study, the biodiesel produced from rapeseed oil (low FFA and water content) with the $\mathrm{Na}_{2} \mathrm{CO}_{3}$ catalyst of $3 \%, 6$ hours processing time, and the methanol: oil molar ratio of 8 was characterized by the FAME content of $96 \%$. With different alkaline salts of $\mathrm{K}_{3} \mathrm{PO}_{4}$ and $\mathrm{Na}_{3} \mathrm{PO}_{4}$, the resulting FAME contents were $96 \%$ and $80 \%$, respectively.

\section{The effect of $\mathrm{Na}_{2} \mathrm{CO}_{3}$ catalyst ratio on the saponification number in the transesterification process}

The saponification number is determined from the length of the carbon chain of the oil or it can be said that the saponification number depends on the molecular weight. The smaller the molecular weight of the oil, the greater the saponification number. A high saponification number also indicates that more reactants are converted into esters (Yusuf, 2018). Figure 11 shows that the saponification number of the biodiesel with $\mathrm{Na}_{2} \mathrm{CO}_{3}$ catalyst has met the SNI Biodiesel value. It is because the ester level of catalyst is above $96 \%$, indicating that there are many triglycerides converted into biodiesel. Triglycerides are compounds with a large molecular weight in an average of $853.55 \mathrm{~g} / \mathrm{mol}$ so that the more triglycerides, the higher the molecular weight, resulting

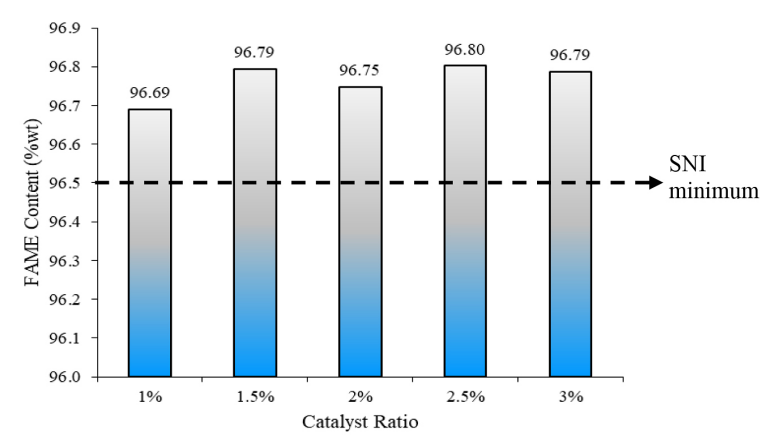

Figure 10. The effect of catalysts ratio on the FAME content of biodiesel in the lower saponification number (Maisarah et al., 2017). The highest saponification number was found in $\mathrm{Na}_{2} \mathrm{CO}_{3}$ of $1.5 \%$ of $199.98 \mathrm{mg} \mathrm{KOH} / \mathrm{g}$ oil. This value fulfilled the SNI for Biodiesel of 196-206 mg KOH/g oil.

\section{The effect of $\mathrm{Na}_{2} \mathrm{CO}_{3}$ catalyst ratio on biodiesel density in the transesterification process}

Biodiesel density affects the distribution of fuel and combustion in the engine so that in biodiesel production, the density value is a significant characteristic to measure. The density of biodiesel is affected by the saponification number, FFA content, water content, and temperature (Nirwana et al., 2004). Figure 12 shows that the biodiesel density on the $\mathrm{Na}_{2} \mathrm{CO}_{3}$ catalyst is high enough.

The small difference in the saponification number, the same reaction temperature, and the evaporated water at the end of the process causes these factors to be neglected. The FFA content in the biodiesel with $\mathrm{Na}_{2} \mathrm{CO}_{3}$ catalyst is high causing the density to increase. Three from five samples meet the SNI for Biodiesel of $860-890 \mathrm{~kg} / \mathrm{m}^{3}$. In contrast to a study by Hidayat (2019), the biodiesel produced had a fairly high density of $923.200 \mathrm{~kg} / \mathrm{m}^{3}$ with castor oil raw material (low FFA), $600 \mathrm{ml}$ methanol, $\mathrm{CaO}$ catalyst ratio of $5 \%$, a processing time of 2 hours, and temperature of $65^{\circ} \mathrm{C}$. Another research using $\mathrm{CaO}$ catalysts was conducted by Haryono (2016). The resulting biodiesel has a density of $868 \mathrm{~kg} / \mathrm{m}^{3}$ with esterified used cooking oil as raw material, the mole ratio of oil: methanol $=1: 15$, a CaO catalyst ratio of $3 \%$, a processing time of 2.5 hours, and a reaction temperature of $65^{\circ} \mathrm{C}$. It shows that the use of $\mathrm{Na}_{2} \mathrm{CO}_{3}$ catalyst is better than other alkaline salts.

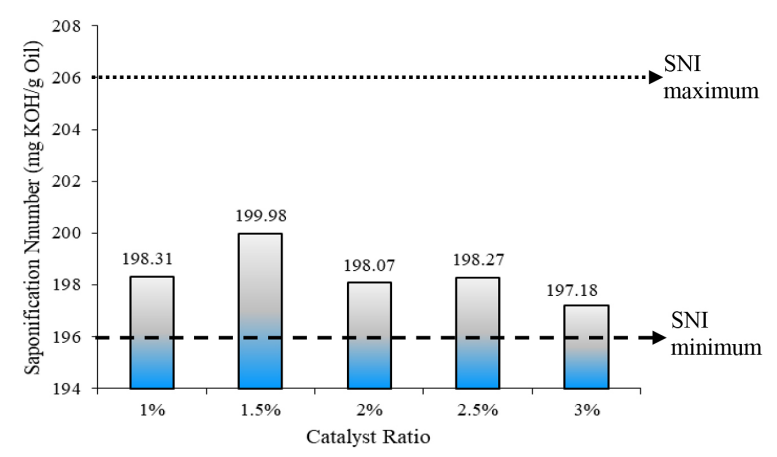

Figure 11. The effect of catalysts ratio on the saponification number of biodiesel 


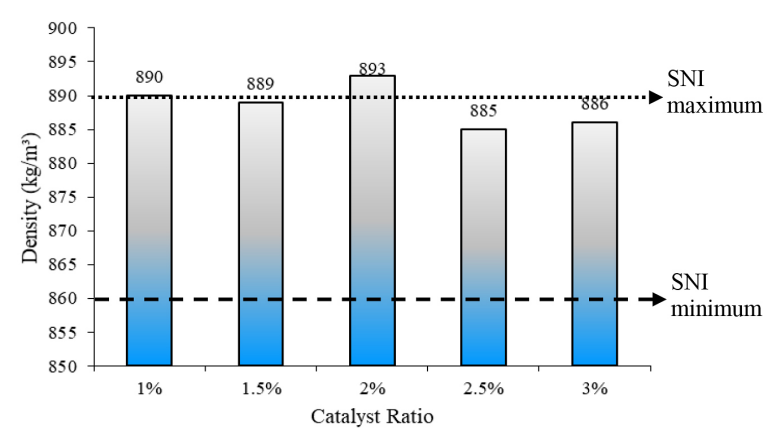

Figure 12. The effect of catalysts ratio on the biodiesel density

The effect of $\mathrm{Na}_{2} \mathrm{CO}_{3}$ catalyst ratio on viscosity

Viscosity is affected by the FFA and glycerol content in biodiesel (Nirwana et al., 2004). The higher the FFA and glycerol content, the higher the viscosity. The value of glycerol in biodiesel using $\mathrm{Na}_{2} \mathrm{CO}_{3}$ catalyst ratio did not vary significantly enough value so that the FFA content has the most effect on viscosity.

Regarding the viscosity value, as shown in Figure 13, the viscosity of biodiesel with $\mathrm{Na}_{2} \mathrm{CO}_{3}$ catalyst is high and does not meet the SNI Biodiesel value. This is because the high FFA in biodiesel with $\mathrm{Na}_{2} \mathrm{CO}_{3}$ catalyst makes the high viscosity value of this biodiesel. The high FFA also makes the separation between the methyl esters, glycerol, and soaps more difficult, affecting the viscosity of biodiesel. High viscosity can result in atomization and pollute the air so that the combustion is incomplete (Laila et al., 2017). Meanwhile, in Saputra's study (2013), the biodiesel from castor oil with a $\mathrm{MgO} / \mathrm{I}_{3}$ catalyst had a viscosity value of $15.76 \mathrm{cSt}$ with a catalyst ratio of 5\%.

\section{The effect of $\mathrm{Na}_{2} \mathrm{CO}_{3}$ catalyst ratio on free glycerol in biodiesel in the transesterifi- cation process}

Free glycerol is a byproduct of biodiesel production. The smaller the free glycerol content, the better the process of washing/refining biodiesel (Furqon et al., 2019). Figure 14 shows that the free glycerol content in the biodiesel using a $\mathrm{Na}_{2} \mathrm{CO}_{3}$ catalyst is almost the same among the varied catalysts ratio.

Before washing, the layer of glycerol and biodiesel in the biodiesel with a $\mathrm{Na}_{2} \mathrm{CO}_{3}$ catalyst is not clear within a day. Therefore, the washing is done on the biodiesel with a $\mathrm{Na}_{2} \mathrm{CO}_{3}$ catalyst, still leaving glycerol which is included in biodiesel.

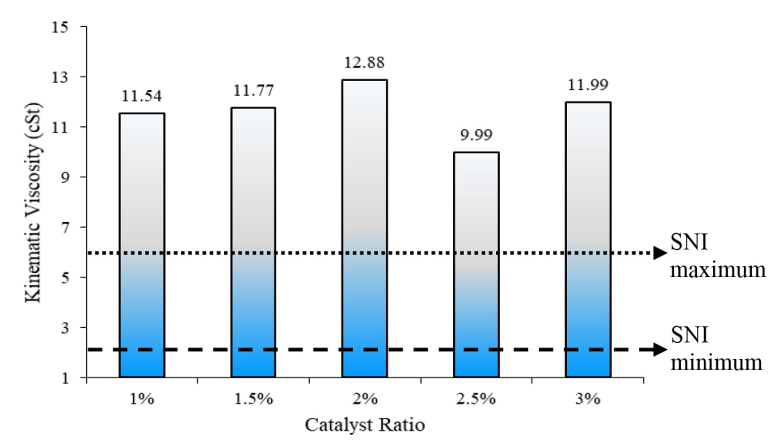

Figure 13. The effect of catalysts ratio on the viscosity of biodiesel

Glycerol is highly undesirable in biodiesel because of its hygroscopic nature so that it can easily oxidize biodiesel and impair its quality (Ningsih et al., 2015). Therefore, the maximum free glycerol content based on SNI for Biodiesel is $0.02 \%$. All samples met the SNI.

\section{The effect of $\mathrm{Na}_{2} \mathrm{CO}_{3}$ catalyst ratio on total glycerol in biodiesel in the transesterifi- cation process}

Total glycerol is the amount of free, partially reacted, and unreacted glycerol. The lower the total glycerol content, the higher the biodiesel conversion value. The partially reacted and unreacted glycerol can be deemed to be bound glycerol (Furqon et al., 2019). Figure 15 shows that the total glycerol content in the biodiesel with a $\mathrm{Na}_{2} \mathrm{CO}_{3}$ catalyst.

The biodiesel with $\mathrm{Na}_{2} \mathrm{CO}_{3}$ catalysts, however, had no total glycerol content that meets the SNI for Biodiesel of a maximum of $0.24 \%$. The lack of transesterification time as the primary cause of the activity of the catalyst has not been optimized to convert triglycerides into biodiesel (Dalimunthe et al., 2016)

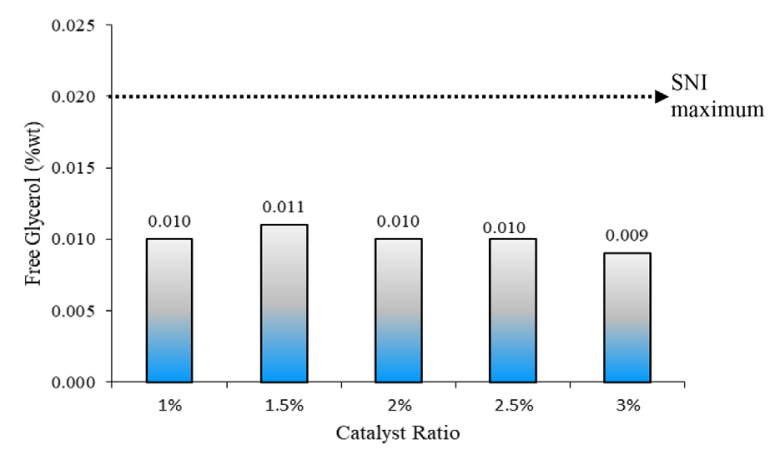

Figure 14. The effect of catalysts ratio on the free glycerol of biodiesel 


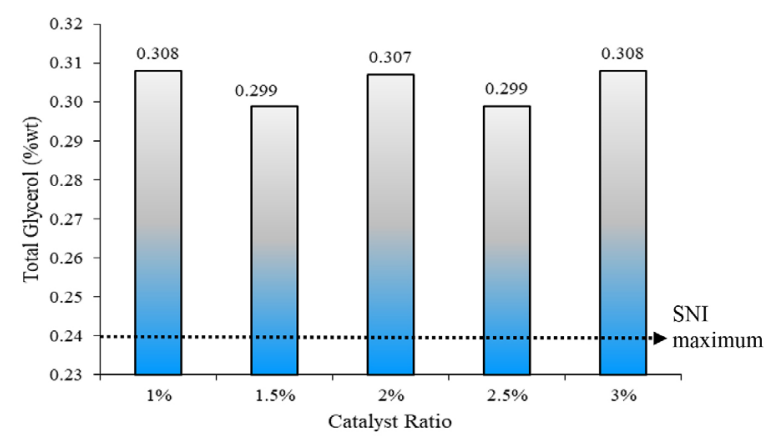

Figure 15. The effect of catalysts ratio on the total glycerol of biodiesel

\section{The effect of $\mathrm{Na}_{2} \mathrm{CO}_{3}$ catalyst ratio on oxidation stability of biodiesel in the transesterification process}

Oxidation stability is the resistance of biodiesel, making it not easily oxidized by air. Oxidation stability determines the length of storing period of biodiesel until oxidized and the characteristics of biodiesel change. Biodiesel oxidation can produce decomposition compounds in the form of acids, aldehydes, esters, ketones, peroxides, or alcohol which can affect engine combustion. The oxidation stability is affected by the unsaturated fatty acid content in biodiesel. Unsaturated fatty acids are highly oxidized easily. The higher the unsaturated fatty acids, the lower the oxidation stability (Amelia et al., 2017). Figure 16 shows that the oxidation stability of the biodiesel on the $\mathrm{Na}_{2} \mathrm{CO}_{3}$ catalyst was achieved for a short time. It indicates that the biodiesel with a $\mathrm{Na}_{2} \mathrm{CO}_{3}$ catalyst is oxidized faster and comprised many unsaturated fatty acids. The presence of unsaturated fatty acids is physically proven or visible. The biodiesel with a $\mathrm{Na}_{2} \mathrm{CO}_{3}$ catalyst, where the entire

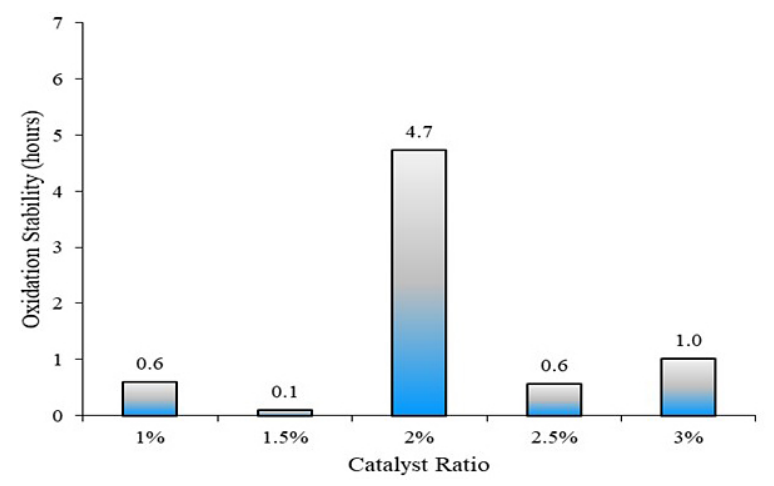

Figure 16. The effect of catalysts ratio on the oxidation stability of biodiesel initial phase is liquid, gradually changes partially to semi-solid.

The longer the oxidation stability, the better the quality of the biodiesel. Therefore, SNI for Biodiesel for oxidation stability is set at least 6 hours. The biodiesel with a $\mathrm{Na}_{2} \mathrm{CO}_{3}$ catalyst of $2 \%$ has oxidation stability of 4.6 hours. This value does not meet SNI of Biodiesel. The decrease in the time of oxidation stability with the addition of a catalyst is caused by the saturation of methanol by the solubility of $\mathrm{Na}_{2} \mathrm{CO}_{3}$, causing the reaction to run poorly (Chanakaewsomboon et al., 2019).

\section{CONCLUSIONS}

On the basis of these results, the higher the ratio of the sulfonated carbon catalyst, the lower the FFA. However, the FFA is increased after reaching the optimum condition. The optimum condition for sulfonated carbon is at a catalyst ratio of $12 \%$ with an FFA of $4.79 \mathrm{mg} \mathrm{KOH} / \mathrm{g}$ oil with a decrease in the FFA of $77.69 \%$. Besides, the optimum reuse of sulfonated carbon catalyst ratio of $12 \%$ is $6.9 \mathrm{mg} \mathrm{KOH} / \mathrm{g}$ oil.

The conversion of the FFA content was $63.89 \%$ for 3 hours of esterification. This number did not meet the standard acid level before being processed in the transesterification. From the 8 characteristics of biodiesel, the $\mathrm{K}_{2} \mathrm{CO}_{3}$ catalyst met 4 characteristics. As the ratio of $\mathrm{Na}_{2} \mathrm{CO}_{3}$ catalysts is greater, the FFA content decreases, the FAME content increases, the density decreases, the viscosity increase, the saponification number increases, the free glycerol tends to remain, the total glycerol decreases, and the oxidation stability increases. The optimum biodiesel characteristics at a $\mathrm{Na}_{2} \mathrm{CO}_{3}$ ratio was $3 \%$. The biodiesel produced has the saponification number of $197.18 \mathrm{mg}$ $\mathrm{KOH} / \mathrm{g}$ oil, free glycerol of $0.09 \%$, FAME content of $96.79 \%$, and density of $886 \mathrm{~kg} / \mathrm{m}^{3}$. These characteristics have met the National Indonesian Standard (SNI of 7182:2015) for Biodiesel.

\section{Acknowledgements}

The authors are very thankful to Ministry of Research, Technology and Higher Education of the Republic of Indonesia for financial support through the Consortium Research Grant in 2018-2019 and to Waste Treatment Engineering Laboratory, Chemical Engineering Department of Universitas Sriwijaya. 


\section{REFERENCES}

1. Abdelrahman B.F., Aziz A.M., Al-Tamer M.H. 2016. Biodiesel Production from Silybum Marianum L. Seed Oil with High FFA Content using Sulfonated Carbon Catalyst for Esterification and Base Catalyst for Transesterification. Journal of Energy Conversion and Management, 108, 255-265.

2. Agustina T.E., Chandra I.M., Nopriyansyah M., Arita S., Hadiah F., Sari T.I., Prakoso T., Heraldy E. 2019. The Extraction of Oil From Cooling Pond Wastewater as A Raw Material for Biodiesel. IOP Conference Series: Materials Science and Engineering, 845(1), 1-9.

3. Amelia C., Andini P., Adhiwardana S., Prasetyani T., Budiastuti H., Widarti S. 2017. Oxidative Resistance and Physical Properties from Palm Fatty Acid Distillate (PFAD) using Antioxidant X. Proceedings of the National Seminar on Chemical Industry Process Engineering, 1, 20-26.

4. Badan Standarisasi Nasional (BSN). 2015. Standar Nasional Indonesia (SNI) 7182: Biodiesel.

5. Balan W.S., Janaun J., Chung C.H., Zhu Z., Haywood S.K., Touhami, D., Chong, K.P., Yaser A.Z., Lee P.C., Zein S.H. 2020. Esterification of Residual Palm Oil Using Solid Acid Catalyst Derived from Rice Husk. Journal of Hazardous Materials, 20, 10-20.

6. Chanakaewsomboon I., Tongurai C., Photaworn S., Kungsanant S., Nikhom R. 2019. Investigation of Saponification Mechanisms in Biodiesel Production: Microscopic Visualization of the Effects of FFA, Water, and the Amount OF Alkaline Catalyst. Journal of Environmental Chemical Engineering. S2213-3437(19)30661-X.

7. Dalimunthe I.S., Restuhadi F., Efendi R. 2016. Synthesis of Biodiesel from Used Cooking Oil using Heterogenous Catalyst Based on Chicken Eggshells. Agricultural Science Journal, 3(2), 1-6.

8. Furqon F., Nugroho A.K., Anshorulloh M.K. 2019. Study of KOH Catalyst in Biodiesel Production using Batch Reverse Flow Biodiesel Reactor. Journal of Hue Agricultural Engineering, 12(1), 22-31.

9. Haryono, Rahayu, I., Yulyati Y.B. 2016. Biodiesel from Used Palm Oil Cooking Oil with $\mathrm{CaO}$ Heterogeneous Catalyst: Study of Determination of $\mathrm{Mol}$ Ratio of Oil/Methanol and Optimal Reaction Time. Exergy Journal, 13(1), 1-5.

10. Hidayat N., Wahab A., Marlina E. 2019. The Effect of $\mathrm{CaO}$ Catalyst on the Production Biodiesel from Jatropa Oil with Transesterification Process. Engineering Journal, 12(1), 15-20.

11. Husin H., Mahidin, Marwan. 2011. Study of Using Catalysts of Coconut Coir Ash, Palm Bunch Ash, and $\mathrm{K}_{2} \mathrm{CO}_{3}$ for Converting Castor Oil to Biodiesel. Reaktor Journal, 13(4), 254-261.
12. Kusumawardani D.S., Agustina T.E., Siddik M.A.B. 2019. Utilization of Palm Oil Wastewater as Raw Material Alternative for Transformer Oil. Indonesia Journal of Fundamental and Applied Chemistry, 5(2), 54-58

13. Laila L. \& Oktavia L. 2017. Study Experiments on Free Fatty Acid and Viscosity of Biodiesel Palm Oil Based from PT. Smart Tbk. Journal of Process Technology and Industrial Innovation, 2(1), 27-31.

14. Maisarah S., Manurung R., Alhamdi M.A., Syahputra A., Ramadhani D.A. 2017. Degummed Palm Oil Methanolysis Process Using Choline Chloride $(\mathrm{ChCl})$ and Glycerol Based Deep Eutectic Solvent (DES) as Co-solvent at Biodiesel Production. International Conference on Sustainable Energy Engineering and Application, 6(10), 128-132.

15. Malins K. 2018. The Potential of $\mathrm{K}_{3} \mathrm{PO}_{4}, \mathrm{~K}_{2} \mathrm{CO}_{3}, \mathrm{Na}-$ ${ }_{3} \mathrm{PO}_{4}$, and $\mathrm{Na}_{3} \mathrm{CO}_{3}$ as reusable alkaline catalysts for pratical application in Biodiesel Production. Journal of Fuel Processing Technology, 179, 302-312.

16. Mantovani S.A. 2020. The Effect of Catalyst Mass dan Reaction Time on the Conversion of Biodiesel from Used Cooking Oil with $\mathrm{CaO}$ Catalyst from Eggshells. Industrial Engineering Scientific Journal, 19(2), 212-222.

17. Nata I.F., Putra M.D., Irawan C., Lee C.K. 2017. Catalytic Performance of Sulfonated Carbon-Based Solid Acid Catalyst on Esterification of Waste Cooking Oil for Biodiesel Production. Journal of Environmental Chemical Engineering, 5, 2171-2175,

18. Ngaosuwan K., Goodwin J.G., Prasertdham P. 2016. A Green Sulfonated Carbon-based Catalyst derived from Coffee Residue for Esterification. Journal of Renewable Energy, 86, 262-269.

19. Ni Z., Li F., Wang H., Wang S., Gao S. 2019. Catalyst Esterification, Kineticts, and Cold Flow Properties of Isobutyl Palmitate. Journal of Fuel, 254, 115368 .

20. Ningsih S.H. 2015. The Effect of Glycerol Plasticizer on Characteristics of Mixed Edible Film from Whey and Jelly. Fundamental and Applied Reasearch on Industrial Engineering Journal, 7(1), 12-20.

21. Nirwana \& Irdoni. 2004. Preliminary Study of Synthesis of Polyester from Palm Oil Raw Materials. International Journal of Science and Applied Technology, 10, 45-57.

22. Niu S., Ning Y., Lu C., Han, K., Yu H., Zhou Y. 2018. Esterification of Oleic Acid to Produce Biodiesel Catalyzed by Sulfonated Activated Carbon from Bamboo. Journal Energy Conversion and Management, 163, 59-65.

23. Nuryanti R., Agustina T.E., Sari T.I. 2019. The Utilization of Palm Oil Mill Effluent for Renewable Energy. Indonesia Journal of Fundamental and Applied Chemistry, 4(3), 116-121. 
24. Otera J. \& Nishikido J. 2009. Esterification: Methods, Reactions, and Application. Wiley-VCH, German.

25. Prihanto A. \& Irawan T.A.B. 2017. The Effect of Temperature, Catalyst Concentration, and Methanol-Oil Ratio on Biodiesel Yield from Used Cooking Oil through Neutralization-Transesterification Process. Methane Journal, 13(1), 30-36.

26. Sangar K.S., Lan C.S., Razali S.M., Farabi M.S., Taufiq Y.H. 2019. Methyl Ester Production from Palm Fatty Acid Distillate (PFAD) using Sulfonated Cow Dung-derived Carbon based Solid Acid Catalyst. Journal of Energy Conversion and Management, 196, 1306-1315.

27. Sani Y.M., Daud W.M.A.W., Aziz A.R.A. 2014. Activity of Solid Acid Catalysts for Biodiesel Production: A Critical Review. Applied Catalysis A:
General Review, 470, 140-161.

28. Saputra D.A. \& Triyono. 2013. Synthesis and Characterization of $\mathrm{MgO} / \mathrm{I}_{3}$-Alumina Catalysts for Transesterification of Castor Oil (Ricinus Communis) into Biodiesel. Process Engineering Journal, 11(3), 30-42.

29. Susilawati \& Supijatno. 2015. Oil Palm Waste Management, Riau. Newsletter of Argonomy Horticulture, 3(2), 203-212.

30. Wahyuni S., Ramli, Mahrizal. 2015. The Effect of Process Temperature and Deposition Time on the Quality of Biodiesel from Used Cooking Oil. Pillar of Physics. 6(10), 33-40.

31. Yusuf M. 2018. Determination of Free Fatty Acid and Saponification Number at PT. Oil Palm Research Center, Medan. Sustainable Cities and Society Journal, 41, 220-226 